\title{
First report of Entamoeba moshkovskii in human stool samples from symptomatic and asymptomatic participants in Kenya
}

\author{
Cecilia Kyany'a $a^{1,2^{*}}$ (D), Fredrick Eyase ${ }^{1,2}$, Elizabeth Odundo ${ }^{1}$, Erick Kipkirui ${ }^{1}$, Nancy Kipkemoi ${ }^{1}$, Ronald Kirera ${ }^{1}$, \\ Cliff Philip ${ }^{1}$, Janet Ndonye ${ }^{1}$, Mary Kiruii, Abigael Ombogo ${ }^{1}$, Margaret Koech'1, Wallace Bulimo ${ }^{1}$ and \\ Christine E. Hulseberg ${ }^{3}$
}

\begin{abstract}
Entamoeba moshkovskii is a member of the Entamoeba complex and a colonizer of the human gut. We used nested polymerase chain reaction (PCR) to differentiate Entamoeba species in stool samples that had previously been screened by microscopy. Forty-six samples were tested, 23 of which had previously been identified as Entamoeba complex positive by microscopy. Of the 46 specimens tested, we identified nine (19.5\%) as E. moshkovskii-positive. In seven of these nine E. moshkovskii-positive samples, either E. dispar or E. histolytica (or both) were also identified, suggesting that co-infections may be common. E. moshkovskii was also detected in both symptomatic and asymptomatic participants. To the best of our knowledge, this is the first report of E. moshkovskii in Kenya.
\end{abstract}

Keywords: Entamoeba, Entamoeba moshkovskii, Diarrhea, Kenya, Nested PCR

\section{Introduction}

Entamoeba moshkovskii is a member of the Entamoeba complex and is morphologically indistinguishable from $E$. dispar and the pathogenic E. histolytica. WHO recommends treatment of both symptomatic (diarrheal) and asymptomatic (non-diarrheal) forms of E. histolytica infection only [1]. Metronidazole or tinidazole followed by iodoquinol or paromomycin is used for treatment of symptomatic $E$. histolytica infections whereas asymptomatic infections are treated using and iodoquinol or paromomycin [2]. Initially considered a free-living amoeba [3], there have been colonization reports of $E$. moshkovskii in humans over the years from Yemen [4], India [5], Indonesia, Colombia [6], Malaysia [7], Tunisia [8], Tanzania [9], and Australia [10]. Beck et al., [9] identified E. moshkovskii carriage in a Tanzanian population. In India, E. moshkovskii was reported not to cause diarrhea but as a cause of mild abdominal discomfort [5], while in Malaysia E. moshkovskii

\footnotetext{
* Correspondence: cc.katunge@gmail.com

${ }^{1}$ United States Army Medical Research Directorate-Africa, P.O. Box 606-00621, Village Market, Nairobi, Kenya

${ }^{2} J$ omo Kenyatta University of Science and Technology, P.O Box 62000-00200, Nairobi, Kenya

Full list of author information is available at the end of the article
}

was isolated from both symptomatic and asymptomatic participants [7]. A 2012 study by Shimokawa and collegues [11] pointed to the possible pathogenicity of $E$. moshkovskii as a cause of diarrhea in mice and infants. Few studies have investigated the distribution of E. moshkovskii in Africa. We sought to screen for E. moshkovskii in stool samples from an ongoing surveillance study on enteric pathogens in Kenya using a PCR based assay.

\section{Materials and methods}

The current study is a retrospective lab-based study nested in an ongoing case-control enteric surveillance study under the US Army Medical Research Directorate Africa at the Microbiology Hub. Archived stool samples collected between April 2013 and September 2014 from out-patient participants enrolled in a 'Surveillance of Enteric Pathogens Causing Diarrheal Illness in Kenya' study across seven participating public hospitals were analysed. Out-patients across all age-groups qualified to be enrolled as case participants (symptomatic) if they presented with 3-4 diarrheal episodes within $24 \mathrm{~h}$ and lasting less than 14 days. Out-patients presenting in the same hospitals with no diarrheal episodes within the last 14 days were enrolled as age-matched controls (asymptomatic). Stool 
aliquots for analysis of parasitic pathogens were suspended in the Mini Parasep ${ }^{\circ}$ SF fecal parasite concentrator (Apacor, Wokingham, United Kingdom) and shipped at $2-8{ }^{\circ} \mathrm{C}$. On arrival at the lab, the samples were centrifuged and a wet-preparation of the filtrate examined under light microscopy. A sample was reported as positive for the Entamoeba complex by either visualizing the trophozoites and/or spherical cysts with 1-4 nuclei. By microscopy, 23 samples were detected as positive for Entamoeba complex. These samples were then matched with their corresponding microscopy negative symptomatic or asymptomatic sample. A total of 46 specimens, 23 (6 symptomatic and 17 asymptomatic) previously identified as positive for Entamoeba complex by microscopy and their corresponding age-matched symptomatic or asymptomatic participants were screened by PCR for Entamoeba complex species. Of the total 46 samples tested 22 were from symptomatic and 24 from asymptomatic participants.

Samples were retrieved from long-term storage at $80^{\circ} \mathrm{C}$ and DNA extracted using the QIAmp DNA stool mini-kit ${ }^{\circ}$, (QIAGEN, Hilden, Germany) as per manufacturer's instructions with slight modifications: incubation time with lysis buffer was $10 \mathrm{~min}$ at $95^{\circ} \mathrm{C}$, incubation time with InhibitEX was $10 \mathrm{~min}$ at room temperature, and incubation time with proteinase- $\mathrm{K}$ was $15 \mathrm{~min}$ at $70^{\circ} \mathrm{C}$. Species detection was carried out using a nested multiplex PCR previously described [12] using primers as listed below. Cycling conditions were as follows for the genus-specific PCR; $96^{\circ} \mathrm{C}$ for 2 min followed by 30 cycles each consisting of $92^{\circ} \mathrm{C}$ for $1 \mathrm{~min}, 56^{\circ} \mathrm{C}$ for $1 \mathrm{~min}$ and $72{ }^{\circ} \mathrm{C}$ for $1 \mathrm{~min}$. For the species-specific PCR, the cycling conditions were maintained and only the annealing temperature adjusted to $48^{\circ} \mathrm{C}$.

The DNA extracts from control strains of $E$. dispar (SAW 760), E. moshkovskii (Laredo) and E. histolytica (HM-1: IMSS) were a generous gift from Dr. Graham Clark of the London School of Tropical Medicine and Hygiene. Nuclease-free water was included as a negative control for each test run. The unknown samples and controls were run on an agarose gel, and amplicons of the seven samples with fragment sizes corresponding to E. histolytica (439 bp), five samples with fragments corresponding to E. moshkovskii (553 bp) and two samples with fragments corresponding to $E$. dispar (174 bp) were purified using ExoSAP-IT kit (ThermoFisher Scientific, Massachusetts, USA) kit and sequenced using standard capillary electrophoresis on a 3500xL Genetic Analyzer (Applied Biosystems, California, USA). The secondary PCR species-specific primers (Table 1) were used for sequencing. Chromatograms were visualized on Chromas and sequences analyzed using DNA sequence assembler v3, www.DnaBaser.com. Consensus sequences were compared to those on GenBank using BLASTn and sequences deposited into GenBank under accession numbers MK142734-
Table 1 List of ribosomal 18S primers used in this study

\begin{tabular}{|c|c|}
\hline \multicolumn{2}{|c|}{ Genus-specific primers (First PCR) } \\
\hline \multirow[t]{2}{*}{ Entamoeba genus } & $\begin{array}{l}\text { E-1 5' TAAGATGCACGAGAGCGAAA 3' } \\
\text { (forward primer) }\end{array}$ \\
\hline & $\begin{array}{l}\text { E-2 5' GTACAAAGGGCAGGGACGTA 3' } \\
\text { (reverse primer) }\end{array}$ \\
\hline \multicolumn{2}{|c|}{ Species-specific primers (Second nested multiplex PCR) } \\
\hline \multirow[t]{2}{*}{ E. histolytica species } & $\begin{array}{l}\text { EH-1 5' AAGCATTGTTTCTAGATCTGAG 3' } \\
\text { (forward primer) }\end{array}$ \\
\hline & $\begin{array}{l}\text { EH-2 5' AAGAGGTCTAACCGAAATTAG 3' } \\
\text { (reverse primer) }\end{array}$ \\
\hline \multirow[t]{2}{*}{ E. moshkovskii species } & $\begin{array}{l}\text { EM-1 5' GAAACCAAGAGTTTCACAAC 3' } \\
\text { (forward primer) }\end{array}$ \\
\hline & $\begin{array}{l}\text { EM-2 5' CAATATAAGGCTTGGATGAT 3' } \\
\text { (reverse primer) }\end{array}$ \\
\hline \multirow[t]{2}{*}{ E. dispar species } & $\begin{array}{l}\text { ED-1 5' TCTAATTTCGATTAGAACTCT 3' } \\
\text { (forward primer) }\end{array}$ \\
\hline & $\begin{array}{l}\text { ED-2 5' TCCCTACCTATTAGACATAGC 3' } \\
\text { (reverse primer) }\end{array}$ \\
\hline
\end{tabular}

MK142737(E. moshkovskii), MH752550-MH752556 (E. histolytica) and MH754938, MH754939 (E. dispar). Maximum likelihood phylogenetic relationships between the species were reconstructed using phyML 3.1 [13] employing the GTR + G model and 100 bootstraps. The tree was rooted to Entamoeba coli FR684433. Chi-square tests of association were performed to investigate possible associations between the presence of $E$. moshkovskii and symptomatic (cases) and/or asymptomatic (controls) infections.

Ethical clearance for this work was obtained from Kenya Medical Research Institute Scientific and Ethical Review Unit (SERU-SSC) and Walter Reed Army Institute of Research (WRAIR) institutional review boards (IRBs) (SSC \# 3365, WRAIR \#1549B).

\section{Results}

Out of the 46 samples tested by PCR, 22 (47.8\%) were positive for Entamoeba complex. Of these, 16 had initially been identified as positive for Entamoeba complex by microscopy (Table 2). Among the 22 PCR-positives, Entamoeba complex species were identified as follows: nine were E. dispar (40.9\%), two were E. moshkovskii (9.1\%), and one was E. histolytica (4.5\%). Combinations of Entamoeba species detected were: three $E$. histolytica and $E$

Table 2 Agreement of Entamoeba species identification by PCR and microscopy

\begin{tabular}{llll}
\hline & Microscopy & Total samples \\
\cline { 2 - 3 } & Positive $(n=23)$ & Negative $(n=23)$ & \\
\hline PCR & & 6 & 22 \\
Positive & 16 & 17 & 24 \\
Negative & 7 & 23 & 46 \\
Total & 23 & & \\
\hline
\end{tabular}


Table 3 Distribution of Entamoeba complex species identified by PCR

\begin{tabular}{|c|c|c|c|c|}
\hline \multirow[t]{2}{*}{ Microscopy } & \multicolumn{2}{|l|}{ PCR } & \multicolumn{2}{|l|}{ Disease status } \\
\hline & Species & Number PCR positive (\%) & Symptomatic (\%) & Asymptomatic (\%) \\
\hline \multirow[t]{5}{*}{ Positive $(n=23)$} & E. dispar only & $9(40.9)$ & $3(33)$ & $6(67)$ \\
\hline & E. moshkovskii only & $2(9.1)$ & $1(50)$ & $1(50)$ \\
\hline & E. histolytica + E. dispar & $2(9.1)$ & $1(50)$ & $1(50)$ \\
\hline & E. histolytica + E. moshkovskii & $2(9.1)$ & $0(0)$ & $2(100)$ \\
\hline & E. dispar + E. moshkovskii & $1(4.5)$ & $0(0)$ & $1(100)$ \\
\hline \multirow[t]{4}{*}{ Negative $(n=23)$} & E. histolytica only & $1(4.5)$ & $1(100)$ & $0(0)$ \\
\hline & E. histolytica + E. dispar & $1(4.5)$ & $0(0)$ & $1(100)$ \\
\hline & E. dispar + E. moshkovskii & $3(13.6)$ & $2(67)$ & $1(33)$ \\
\hline & E. histolytica + E. moshkovskii + E. dispar & $1(4.5)$ & $1(100)$ & $0(0)$ \\
\hline
\end{tabular}

.dispar (13.6\%), two E. histolytica + E. moshkovskii (9.1\%), four E. moshkovskii and E. dispar (18.2\%) and one $E$. histolytica and E. dispar and E. moshkovskii (Table 3) (Fig. 1).

E. moshkovskii mono-infection was identified in two samples and in seven samples as co-infection with either E. dispar, E. histolytica or both. Of the nine PCRpositive E. moshkovskii samples, five had previously been identified by microscopy as Entamoeba complex, while the remaining were missed identifications. E. moshkovskii was identified both in symptomatic and asymptomatic participants with no statistically significant differences. Of the nine bands corresponding to E. moshkovskii band size (553 $\mathrm{bp}$ ), four were very faint and could not be sequenced. This could be attributed to possible low parasite copy number in the stool specimens. One sample failed to sequence thus sequence analysis was performed on only four high-quality bands. Sequence analysis of E. moshkovskii bands revealed 99\% identity to the Laredo reference strain of $E$. moshkovskii (KP722605.1). Reconstruction of phylogenetic relationships revealed distinct species-specific clustering (Fig. 2).

\section{Discussion}

This study speciated members of the Entamoeba complex from stool specimens using PCR. We then sequenced the E. moshkovskii-positive samples to confirm proper species identification and constructed a phylogenetic tree. To the best of our knowledge, this is the first survey of the distribution of Entamoeba species in clinical samples originating from Kenyan symptomatic and asymptomatic participants.

Although the number of samples tested in this study is fairly small, co-infections among species of the Entamoeba complex appear to be common. We also detected E. moshkovskii alongside E. dispar and E. histolytica and noted a high frequency of detection for $E$. dispar. This detection of E. moshkovskii alongside these two species is also consistent with other reports that Entamoeba species co-circulate

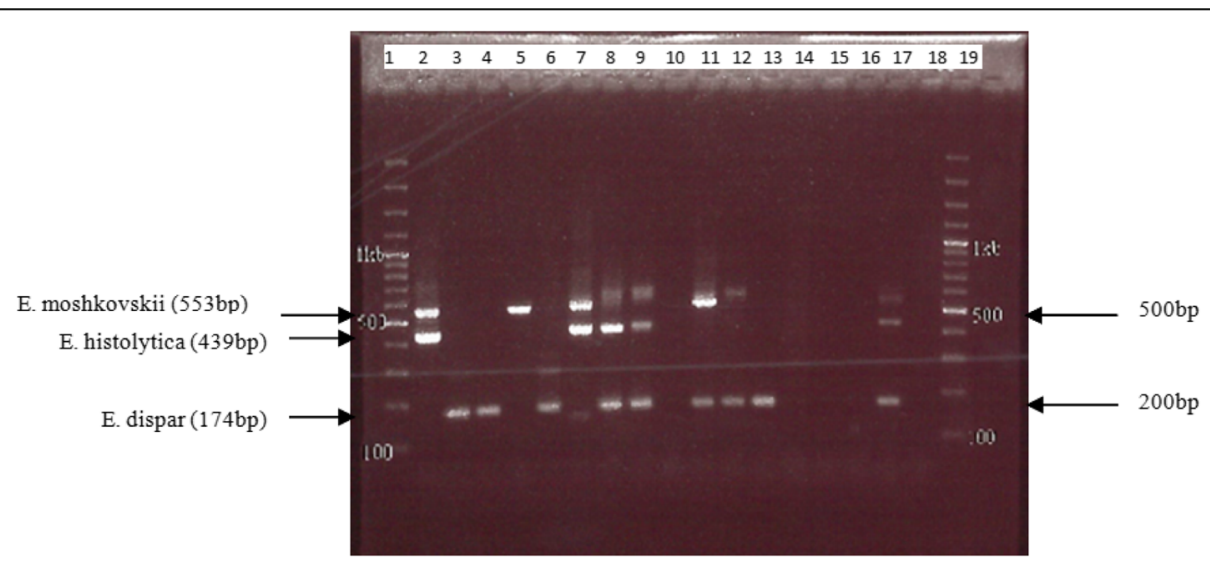

Fig. 1 Species differentiation of Entamoeba complex species. Lane 1 and 19 are $100 \mathrm{bp}$ molecular weight ladder. Lane 2- E. histolytica and E. moshkovskii co-infection, lane 3, 4 - E. dispar (mono-infection), lane 5- E. moshkovskii (mono-infection), lane 6 - E. dispar (mono-infection), lane 7E. histolytica and E. moshkovskii, lane 8,9- E. dispar and E. histolytica, lane 10 - negative, lane 11,12-E. dispar and E. moshkovskii, lane $13-E$. dispar, lane 14, 15, 16 - negative, lane 17 - positive control (E. dispar, E. histolytica, E. moshkovskii), lane 18 - negative control 


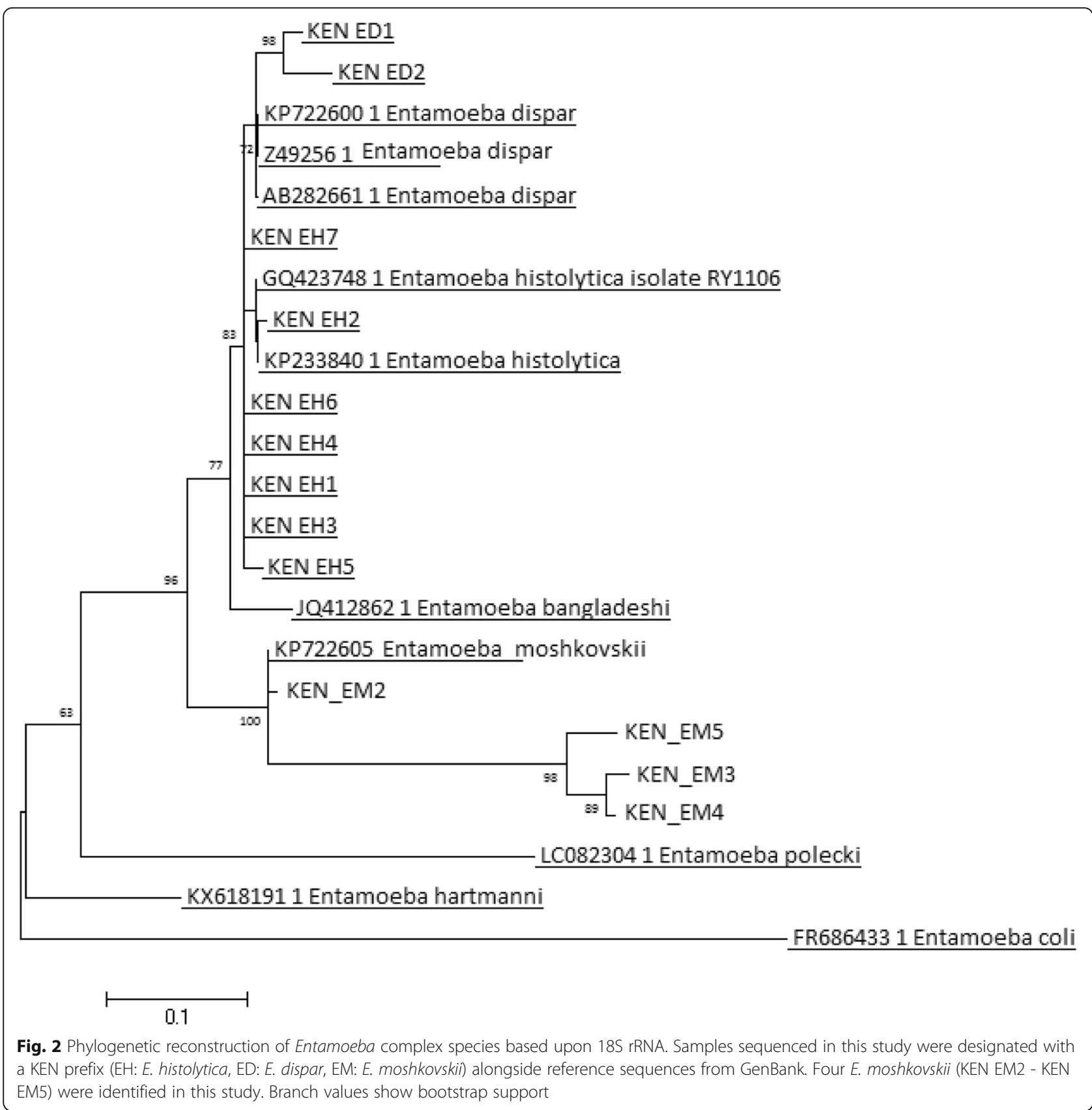

in Entamoeba endemic areas [14]. Previous Kenyan studies [15-21] have largely focused on microscopic identification of Entamoeba complex and/or molecular identification of $E$. histolytica. This has left a gap in our understanding of the epidemiological distribution of Entamoeba species in Kenya. Paucity of differentiation studies has in addition denied important assessments as to whether they contribute to gastrointestinal disease in humans. A recent molecular epidemiological study of Entamoeba species, involving asymptomatic children from western Kenya, using a nested PCR assay, did not detect any E. moshkovskii infections
[17]. Although Matey et al., did not detect E. moshkovskii in their study population, it is possible that E. moshkovskii infections have been in circulation in Kenya and are only now being identified.

This study focused on identifying three members of the Entamoeba complex thus it is possible that some of the microscopy misidentifications could be other members of the broader Entamoeba genus. For instance, cysts of E. hartmanii can be misidentified as Entamoeba complex since despite being relatively smaller, they too possess 1-4 nuclei. Furthermore, the missed identifications 
by microscopy are often attributable to a low number of cysts in the stool, degraded trophozoites, varying technical skill among technicians, human error and subjectivity.

Phylogenetic analyses showed Entamoeba complex spp. were closely related to but genetically distinct from other Entamoeba spp. (E. coli, E.polecki, E. hartmanii). E. moshkovskii, E. dispar and E. histolytica grouped into distinct clusters. This grouping was evidence of correct species identification and confirmation of the PCR assay results.

There are a number of reasons why it is important to establish the molecular epidemiology of members of the Entamoeba complex in Kenya, the most immediate being to accurately treat in endemic areas like Kenya. This report highlights the need for continued epidemiology and PCR-based testing on a larger sample set to establish the burden of E. moshkovskii in the Kenyan population and monitor the patterns of infection.

\section{Disclaimers}

The material has been reviewed by the Walter Reed Army Institute of Research. There is no objection to its publication. The opinions or assertions contained herein are the private views of the author and are not to be construed as official, or as reflecting true views of the Department of the Army or the Department of Defense. The investigators have adhered to the policies for the protection of human subjects as prescribed in AR 70-25. This work has been published with the permission of the USAMRD-A, WRAIR and Director of KEMRI.

\section{Authors' contributions}

Conceptualization: CEH, CK, EO. Data Curation: CK, EO, EK, NK, RK, CP, JN, MK, $\mathrm{AO}, \mathrm{MK}$.

Formal analysis: CK, WB, FE, EO. Funding Acquisition: CEH, EO. Investigation: CK, EO, EK, NK, RK, CP, JN, MK, AO, MK. Methodology: ECH, CK, EO, WB, FE. Supervision: $C E H, W B, F E$.

Validation: CEH, WB, FE. Writing- Original draft preparation: CK. WritingReview and Editing: CK, FE, WB, CEH,EO. All authors read and approved the final manuscript.

\section{Funding}

This work is funded by the Armed Forces Health Surveillance Branch (AFHSB) and its Global Emerging Infections Surveillance (GEIS) Section. The funding body had no role in the design of the study, data collection, analysis, and interpretation of data or in writing the manuscript.

\section{Availability of data and materials}

All data generated or analysed during this study are included in this published article.

\section{Ethics approval and consent to participate}

Ethical clearance for this work was obtained from Kenya Medical Research Institute Scientific and Ethical Review Unit (SERU-SSC) and Walter Reed Army Institute of Research (WRAIR) institutional review boards (IRBs) (SSC \# 3365, WRAIR \#1549B).

\section{Consent for publication}

Not applicable

\section{Competing interests}

The authors declare that they have no competing interests.

\section{Author details}

'United States Army Medical Research Directorate-Africa, P.O. Box 606-00621, Village Market, Nairobi, Kenya. ${ }^{2} J o m o$ Kenyatta University of Science and Technology, P.O Box 62000-00200, Nairobi, Kenya. ${ }^{3}$ United States Army Medical Research Institute of Infectious Diseases, Fort Detrick, Maryland, USA.
Received: 26 June 2019 Accepted: 14 November 2019

Published online: 17 December 2019

\section{References}

1. Amoebiasis. Releve epidemiologique hebdomadaire. 1997 72(14):97-99. PubMed PMID: 9100475. Epub 1997/04/04. eng.

2. Farthing MJ. Treatment options for the eradication of intestinal protozoa. Nat Clin Pract Gastroenterol Hepatol. 2006;3(8):436-45 PubMed PMID: 16 883348. Epub 2006/08/03. eng.

3. Neal RA. Studies on the morphology and biology of Entamoeba moshkovskii Tshalaia, 1941. Parasitology. 1953;43(3-4):253-68 PubMed PMID: 13111812. Epub 1953/11/01. eng.

4. Al-Areeqi MA, Sady H, Al-Mekhlafi HM, Anuar TS, Al-Adhroey AH, Atroosh WM, et al. First molecular epidemiology of Entamoeba histolytica, E. dispar and E. moshkovskii infections in Yemen: different species-specific associated risk factors. Trop Med Int Health. 2017;22(4):493-504 PubMed PMID: 28151567. Epub 2017/02/06. eng.

5. Parija SC, Khairnar K. Entamoeba moshkovskii and Entamoeba disparassociated infections in Pondicherry, India. J Health Popul Nutr. 2005;23(3): 292-5 PubMed PMID: 16262027. Epub 2005/11/03. eng.

6. Fonseca JA, Heredia RD, Ortiz C, Mazo M, Clavijo-Ramirez CA, Lopez MC. Identification of Entamoeba moshkovskii in treated waste water used for agriculture. EcoHealth. 2016;13(1):156-60 PubMed PMID: 26732073. Epub 2016/01/07. eng.

7. Anuar TS, Al-Mekhlafi HM, Ghani MK, Azreen SN, Salleh FM, Ghazali N, et al. First molecular identification of Entamoeba moshkovskii in Malaysia. Parasitology. 2012;139(12):1521-5 PubMed PMID: 22939193. Epub 2012/09/04. eng.

8. Ayed SB, Aoun K, Maamouri N, Abdallah RB, Bouratbine A. First molecular identification of Entamoeba moshkovskii in human stool samples in Tunisia. Am J Trop Med Hyg. 2008;79(5):706-7 ubMed PMID: 18981508. Epub 2008/ 11/05. eng.

9. Beck DL, Dođan N, Maro V, Sam NE, Shao J, Houpt ER. High prevalence of Entamoeba moshkovskii in a Tanzanian HIV population. Acta Trop. 2008; 107(1):48-9 PubMed PMID: 18471796.

10. Fotedar R, Stark D, Beebe N, Marriott D, Ellis J, Harkness J. PCR detection of Entamoeba histolytica, Entamoeba dispar, and Entamoeba moshkovskii in stool samples from Sydney, Australia. J Clin Microbiol. 2007;45(3):1035-7 PubMed PMID: 17229864. Pubmed Central PMCID: PMC1829108. Epub 2007/01/19. eng.

11. Shimokawa C, Kabir M, Taniuchi M, Mondal D, Kobayashi S, Ali IK, et al. Entamoeba moshkovskii is associated with diarrhea in infants and causes diarrhea and colitis in mice. J Infect Dis. 2012;206(5):744-51 PubMed PMID: 22723640. Pubmed Central PMCID: PMC3491739. Epub 2012/06/23. eng.

12. Khairnar K, Parija SC. A novel nested multiplex polymerase chain reaction (PCR) assay for differential detection of Entamoeba histolytica, $E$ moshkovskii and E dispar DNA in stool samples. BMC Microbiol. 2007;7:47 PubMed PMID: 17524135.

13. Guindon S, Dufayard JF, Lefort V, Anisimova M, Hordijk W, Gascuel O. New algorithms and methods to estimate maximum-likelihood phylogenies: assessing the performance of PhyML 3.0. Syst Biol. 2010;59(3):307-21 PubMed PMID: 20525638. Epub 2010/06/09. eng.

14. Heredia RD, Fonseca JA, López MC. Entamoeba moshkovskii perspectives of a new agent to be considered in the diagnosis of amebiasis. Acta Tropica. 2012;123(3):139-45.

15. Mwendwa F, Mbae CK, Kinyua J, Mulinge E, Mburugu GN, Njiru ZK. Stem loop-mediated isothermal amplification test: comparative analysis with classical LAMP and PCR in detection of Entamoeba histolytica in Kenya. BMC Res Notes. 2017;10(1):142 PubMed PMID: 28359328. Pubmed Central PMCID: PMC5374617. Epub 2017/04/01. eng.

16. Njuguna C, Njeru I, Mgamb E, Langat D, Makokha A, Ongore D, et al. Enteric pathogens and factors associated with acute bloody diarrhoea, Kenya. BMC Infect Dis. 2016;16:477 PubMed PMID: 27600526. Pubmed Central PMCID: PMC5012060. Epub 2016/09/08. eng.

17. Matey EJ, Tokoro M, Nagamoto T, Mizuno T, Saina MC, Bi X, et al. Lower prevalence of Entamoeba species in children with vertically transmitted HIV infection in Western Kenya. AIDS. 2016;30(5):803-5 PubMed PMID: 2691 9716. Epub 2016/02/27. eng.

18. Easton AV, Oliveira RG, O'Connell EM, Kepha S, Mwandawiro CS, Njenga SM, et al. Multi-parallel qPCR provides increased sensitivity and diagnostic breadth for gastrointestinal parasites of humans: field-based inferences on 
the impact of mass deworming. Parasit Vectors. 2016;9:38 PubMed PMID: 26 813411. Pubmed Central PMCID: 4729172. Epub 2016/01/28. eng.

19. Mbae CK, Nokes DJ, Mulinge E, Nyambura J, Waruru A, Kariuki S. Intestinal parasitic infections in children presenting with diarrhoea in outpatient and inpatient settings in an informal settlement of Nairobi. Kenya BMC Infect Dis. 2013;13:243 PubMed PMID: 23705776. Pubmed Central PMCID: 3673844 Epub 2013/05/28. eng.

20. Kamau P, Aloo-Obudho P, Kabiru E, Ombacho K, Langat B, Mucheru O, et al. Prevalence of intestinal parasitic infections in certified food-handlers working in food establishments in the City of Nairobi, Kenya. J Biomed Res. 2012;26(2):84-9 PubMed PMID: 23554735. Pubmed Central PMCID: PMC35 97323. Epub 2013/04/05. eng

21. Swierczewski BE, Odundo EA, Koech MC, Ndonye JN, Kirera RK, Odhiambo $\mathrm{CP}$, et al. Surveillance for enteric pathogens in a case-control study of acute diarrhea in Western Kenya. Trans R Soc Trop Med Hyg. 2013;107(2):83-90 PubMed PMID: 23222955. Epub 2012/12/12. eng.

\section{Publisher's Note}

Springer Nature remains neutral with regard to jurisdictional claims in published maps and institutional affiliations.

Ready to submit your research? Choose BMC and benefit from:

- fast, convenient online submission

- thorough peer review by experienced researchers in your field

- rapid publication on acceptance

- support for research data, including large and complex data types

- gold Open Access which fosters wider collaboration and increased citations

- maximum visibility for your research: over $100 \mathrm{M}$ website views per year

At $B M C$, research is always in progress.

Learn more biomedcentral.com/submissions 